\title{
Full-scale testing of water intake pumps of pumping stations
}

\author{
Khasanov Bakhriddin", Azimov Azam and Djurabekov Alisher \\ Tashkent Institute of Irrigation and Agricultural Mechanization Engineers, 100007, Tashkent, \\ Uzbekistan
}

\begin{abstract}
This article is devoted to methods analysis and systems for maintaining the forebay operating modes of pumping stations, which the minimum cost of resources is provided. In modern conditions there is a need to implement measures and solutions to improve the operational performance of pumping stations, which would lead to a decrease in the cost of water supplied. Such activities include the development of methods and systems for the management and maintenance of stations operating modes, which provide the minimum cost of resources. Based on observations, the uneven operation of pumping units over time and as a result of imperfect design of advance cells, the design hydraulic indicators of flow and operational parameters of pumping stations deteriorate. The relevance hydraulic research of forebay regimes and water intakes indicated at a number of meetings on pumps quality. With the development of the recommended set of measures, it is possible to save water and energy resources. The purpose of the work was to conduct full-scale testing of forebay on a large pumping stations in operation, to develop a new design of forebay and its hydraulic calculation. During work performing, energy-hydraulic methods for determining the parameters of pumping units were used.
\end{abstract}

\section{Introduction}

In modern conditions there is a need to implement measures and solutions to a number of tasks to improve the operational performance of pumping stations, which would lead to a decrease in the cost of water supplied. Among such measures include keeping the development of such methods and modes of operation systems forebays pumping stations, which are provided at the minimum resource costs.

As the results of observation, due to non-uniform operation of pump units of time and as a result of imperfect structure forebays deteriorate hydraulic flow design parameters, operating parameters of the pumping stations. When developing new designs forebays may provide savings of water and energy resources.

Institutes Institute of Irrigation and Water Problems and Tashkent Institute of Irrigation and Agricultural Mechanization Engineers Uzbekistan were conducted full-scale tests of samples of pumps that investigated the effects of cavitation on pressure pulsation behind the impeller of pumps $[1,2,3,4]$. At Amu-Zang pumping stations 1.2, the control tests

\footnotetext{
"Corresponding author: mr.bakhridin@mail.ru
} 
included the determination of the actual parameters of the pumps at the time of the survey, including feed, pump head, power consumed by the electric motor, unit efficiency and pump. Control tests were subject to the same type of pump units with the following design parameters:

Pump - flow, $\mathrm{m}^{3} / \mathrm{s}-25 \ldots 27$, pressure, $\mathrm{m}-40 \ldots$... 38, suction height (backwater), $\mathrm{m}$ - 5.2, efficiency - $86 \%$;

Electric motor - power, $\mathrm{kW}-12,500$, rotor speed, min-1 - 214, efficiency - 96.9\%.

During operating the units, the following modes are possible: insufficient (sufficient) level of the downstream, full (partial) charging of the siphon of the suction chambers, operation (during start-up) on the closed butterfly valve.

\section{Main part}

The supply of pumping stations is determined by the work schedule of the entire cascade, the number and station numbers of the included units depend on their readiness and technical condition. Stopping the pumps or partially reducing the flow during prolonged throttling with butterfly valves violates the steady-state synchronous operation mode of the cascade, makes it necessary to turn off the units on the upstream NS [6,7]. The smallest hydraulic resistance of siphon water intake are pump units No. 2-0.36m and No. $4-0.3 \mathrm{~m}$, which can be explained by better tightness and streamline siphon chambers of these units.

The pressure loss of pumping units No. 4 and No. 5 is $0.6 \ldots 0.8 \mathrm{~m}$ less than that of pumping units No. 1 and No. 2, which is obviously due to the lower roughness of the internal surface of those pipelines that have a shorter service life. It should be noted that the actual diameter of the impellers is unknown, and a decrease in the water level in the avantchamber during tests, $294.27 \mathrm{~m}$ for pumping units No. 4 (start of testing) to $294.04 \mathrm{~m}$ for No. 5 (the end of testing).

A more correct comparison of pumping units can be made analytically by conducting their parameters to a pressure of $40.0 \mathrm{~m}$, corresponding to the operating point of the characteristics of the reference pump (Table 1).

Table 1. The parameters of the pumps

\begin{tabular}{|l|c|c|c|}
\hline \multirow{2}{*}{ Options } & Based on & \multicolumn{2}{c|}{ Pump units } \\
\cline { 3 - 4 } & project & 1 & 2 \\
\hline pressure, $\mathrm{M}$ & 40,0 & 40,0 & 40,0 \\
\hline Water supply, ${ }^{3} / \mathrm{c}$ & 25,0 & 23,71 & 22,25 \\
\hline Power, kw & 11400 & 11230 & 10910 \\
\hline Unitefficiency, \% & 86,0 & 82,8 & 83,6 \\
\hline Reducedefficiency, \% & 5,0 & 3,2 & 2,4 \\
\hline
\end{tabular}

As can be seen from the table, the units can reduce the flow of $1.75 \ldots 1.29 \mathrm{~m}^{3} / \mathrm{s}$ and work with a reduced by $2.4 \ldots 4.2 \%$ efficiency (Specifications 26-06-1196 allow for operating efficiency to decrease by $5 \%$ ) .

In the practice of operating the units, there are modes with a partial or full discharge of one of the siphon water intake chambers. The water level in the discharged chamber drops by $0.8 \ldots 1.0 \mathrm{~m}$ and the unit operates almost as a single camera. In order to calculate the efficiency in this case, the pressure is taken according to the level in the charged chamber $[12,13]$. Cavitation is one of the main negative factors that reduce the durability of pumps, therefore, to develop measures for its prevention and elimination, full-scale full-scale cavitation testing of pumps are required. Tests of these modes were carried out on the pump 
unit number 1 . The following results were obtained (table 2).

Table 2. Parameters of the pump with a discharged suction chamber.

\begin{tabular}{|l|c|c|c|c|}
\hline \multirow{2}{*}{ Modefeature } & \multicolumn{4}{|c|}{ Options } \\
\cline { 2 - 5 } & $\begin{array}{c}\text { supply, } \\
\mathrm{m}^{3} / \mathrm{s}\end{array}$ & pressure, $\mathrm{m}$ & power, $\mathrm{kWt}$ & $\begin{array}{c}\text { Pumpefficiency, } \\
\%\end{array}$ \\
\hline Suctionchamberfullycharged & 25,98 & 36,8 & 11240 & 86,1 \\
\hline Partialairleak & 25,95 & 36,8 & 11340 & 85,3 \\
\hline $\begin{array}{l}\text { One chamber is completely } \\
\text { discharged }\end{array}$ & 25,36 & 37 & 11220 & 84,6 \\
\hline
\end{tabular}

For the Amu-Zang 2 pumping station, a $2000 \mathrm{~kW} 16 / 63-\mathrm{A} 3$ pump was used with an impeller turned to the following parameters: flow rate $15 \mathrm{~m} 3 / \mathrm{s}$, head 47 meters.

The functions of the blocking construction at pumping stations are performed by a siphon water intake connecting the (separating) suction pipes of the pumps and the forebays through 10 (two for each pump) siphons [14,15]. Siphon water intake has technical advantages compared with the closures, namely: the absence of moving structures, silo grooves and sill, seals, lifting mechanisms for moving the closures; simplicity of blocking the flow at the inlet to the suction pipes of the pumps (it is enough to open the valve on the siphon hood). A siphon water intake in such a design (with a flow gap between the siphon and the elongated suction chamber) objectively neutralizes the unfavorable flow structure formed in the avant-chamber, levels the flow at the inlet to the pump impeller.

At the same time, the siphon water intake has difficulty in optimizing the high-altitude position of the siphon ridge in conditions of sensitive (according to long-term data up to 4 $\mathrm{m})$ seasonal fluctuations of the water level in the water source. The difficulty in choosing the mark of the siphon crest is that when the mark is overestimated, the main functional efficiency of the siphon (guaranteed break of the flow when the pump stops) increases, and the energy efficiency (capacity for water rise) decreases $[8,9,10]$. When understating - the opposite. So, after several years of operation of pumping stations, it turned out that when the level in the avant-chamber increases above the crest of the siphon and overflows water through it into the suction chambers, there is a threat of flooding of the pumping stations through the unit disassembled for repair, it is impossible seals on a closed unit. Therefore, according to a concerted decision, the crest of the siphons was increased to the detriment of hydraulic flow. According to field measurements of the water levels before and after the siphon of the backup unit No. 3, made by the authors of the report, the magnitude of the elevation of the ridge was $0.9 \ldots 0.94 \mathrm{~mm}$.

Siphon as hydraulic resistance causes additional pressure loss. Measurements taken at the siphons units in May-June 2014, July 2018 are presented in Table 3.

Table 3. The level water drop in siphons.

\begin{tabular}{|c|c|c|c|}
\hline \multirow{2}{*}{$\begin{array}{c}\text { Siphon chamber } \\
\text { number }\end{array}$} & \multicolumn{2}{|c|}{ Water level, absolutemeters } & \multirow{2}{*}{ difference, $\mathrm{m}$} \\
\cline { 2 - 3 } & In forebays & After siphon & \\
\hline 1 & 2 & 3 & 4 \\
\hline 1 & 295,36 & 294,96 & 0,40 \\
\hline 1 & 2 & 3 & 4 \\
\hline 2 & 295,14 & 294,8 & 0,34 \\
\hline 3 & 295,14 & 294,77 & 0,37 \\
\hline 4 & 295,14 & 294,76 & 0,38 \\
\hline 7 & 295,14 & 294,79 & \\
\hline
\end{tabular}




\begin{tabular}{|l|l|l|l|}
\hline 8 & 295,14 & 294,78 & 0,36 \\
\hline 1 & 294,76 & 294,34 & 0,42 \\
\hline 2 & 294,76 & 294,34 & 0,42 \\
\hline 3 & 294,76 & 294,36 & 0,40 \\
\hline 4 & 294,76 & 294,40 & 0,36 \\
\hline 7 & 294,76 & 294,40 & 0,36 \\
\hline
\end{tabular}

Accepting the average value of the pressure loss in the siphon $(0.36 \mathrm{~m})$ for the average operation - with a calculated pump head of $40 \mathrm{~m}$ - it can be concluded that the reduction in the unit's supply due to the additional hydraulic resistance in the modernized (extended) siphon is approximately $0.3 \ldots 0.4 \mathrm{~m}^{3} / \mathrm{s}$.

In the absence of tightness in the siphon, the charging time of the siphons is increased. The leakage of air into the siphon causes the formation of an air cushion in the throat section of the siphon, which increases the pressure loss in the siphon.

Such a picture was observed in the siphon chambers of unit No. 1, where, due to nondensities in the places where the vacuum tubes pass through the top concrete part of the siphon, air leaks from the atmosphere to the inside of the siphon. As a result of air leaks, the siphon works with an incomplete cross section, the water level difference on the siphon increases, causing a decrease in the backwater, feed and efficiency of the unit $[11,16]$. Especially, the hydraulic conditions of the water supply from the advance chamber when air is sucked through the whirlpool funnels (figure) affect the modes of pumping units.

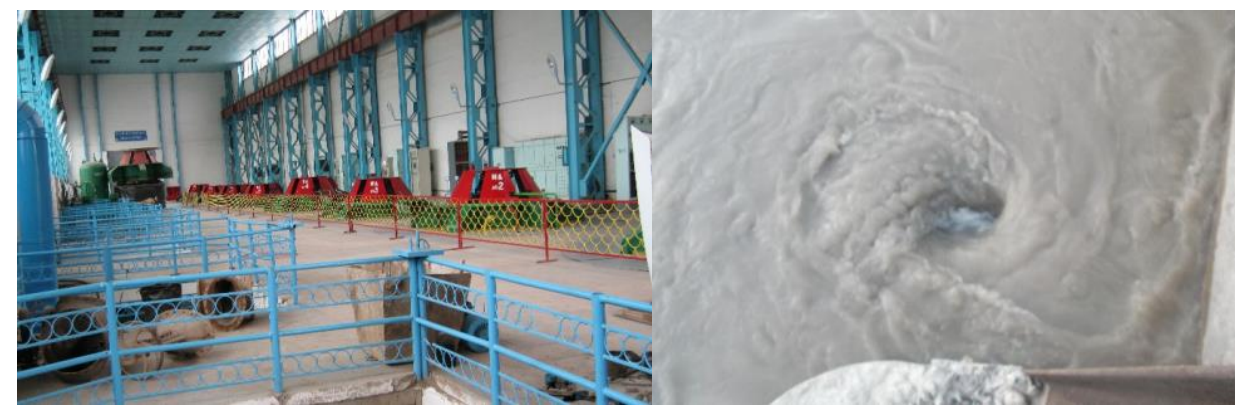

Fig. 1. Whirlpool funnels in the intake and machine room pumping station Amu-Zang 2

In many cases, cavitational phenomena in the impeller area have a great effect on pressure pulsation. From the point of view of the reliability of the experimental data obtained, it is of interest to evaluate the measure of the influence of these phenomena on the characteristics of non-stationarity.

Knowledge of pressure pulsations depending on the head unit and the cavitation coefficient corresponding procedure allows to build experiments which determine the nature of such flow. Let us assume that the transient movement of water through the flow of the pump obeys the Navier-Stokes equation $[2,5]$.

Assuming that gravity does not define the nature of the flow (the cases of influence of wave propagation in pools of hydro excluded), we can write the equation in the form

$$
\frac{\partial \overline{\mathrm{V}}}{\partial \mathrm{t}}+\left(\overline{\mathrm{V}}_{\nabla}\right) \overline{\mathrm{V}}=-\frac{1}{1 \rho} \operatorname{grad} p+v \Delta \overline{\mathrm{V}}
$$

where $\overline{\mathrm{V}}$ - flow velocity vector; $\mathrm{p}$ - pressure; $p$ - density; $v$ - kinematic viscosity; $\mathrm{t}$ time. 
Introducing the dimensionless velocity ${ }^{\prime}$, pressure $\mathrm{p}^{\prime}$, and time $\mathrm{t}^{\prime}$, we write equation (1), in dimensionless form

$$
\operatorname{Sh} \frac{\partial\left(\bar{j} v^{\prime}\right)}{\partial t}+\left(j v^{\prime} \nabla\right) \bar{j} v^{\prime}=-E u \operatorname{grad} p^{\prime}+\frac{1}{\operatorname{Re}} \Delta \bar{j} v^{\prime}
$$

where $\overline{\mathrm{j}}$ - unit velocity vector $\bar{V} ; \mathrm{Sh}=\frac{L}{\mathrm{VT}}-$ Strouhal number;

$\mathrm{Re}=\frac{V L}{v}-$ Reynolds number; $\mathrm{Eu}=\frac{\Delta \rho}{\rho \mathrm{V}^{2}}-$ Euler number.

The transient process is assumed to be periodic. Then the condition of similarity of flows will be satisfied if

$$
\begin{gathered}
\text { Sh=idem; } \\
\text { Re=idem; } \\
j=\text { idem } .
\end{gathered}
$$

The latter condition means the geometric similarity of the velocity plan. The consequence of these three conditions is

$E u=i d e m$.

If the nonstationary flow is the result of the addition of several periodic forms, then from the generality of equation (1) it follows that for such component flows, with some characteristic velocities $v_{0 i}$, condition will be automatically met $\frac{v_{0 i}}{v_{0}}=$ idem and constancy of the relations of the corresponding Strouhal numbersone of which should be taken as the "main" number Sho.

When testing the models of the unit, the main non-stationarity created by the impeller vane system in absolute motion is characterized by the Strouhal number Sho, which is related to the given rotation numbers $n_{i}$ by the relation $[2,3]$

$$
S h_{0}=\frac{f R}{V} .
$$

here $f$ - a frequency of the forming the curls, $R$ - a hydraulic diameter soaking up pipes, $V$ - a velocity of the flow.

When testing the models of the unit, the main non-stationarity created by the impeller vane system in absolute motion is characterized by the Strouhal number $\mathrm{Sh}_{\mathrm{o}}$, which is related to the given rotation numbers $\mathrm{n}$ by the relation $[2,3]$.

$$
\begin{aligned}
\lambda & =\frac{D_{I}}{\mathrm{~T} \sqrt{\mathrm{H}}}, \\
\tau & =\frac{\mathrm{T} n}{60} .
\end{aligned}
$$

here $D_{I}$ - impeller diameter; $T$ - characteristic period of non-stationary process; $H$ напор; $n$ - impeller speed; $\lambda$ - reduced frequency; $\tau$ - relative period.

If pressure pulsation is caused by phenomena not described by equation (1) (cavitation processes, discontinuous currents), then the fulfillment of similarity conditions (3) is not enough. For cavitation phenomena, for example, the observance of a known condition is additionally necessary. $\sigma_{y}=$ const. 


\section{Discussion}

Discussion of the article was held at a number of international conferences.

The main provisions of the questions on the choice of materials resistant to cavitation abrasive wear are given in $[2,3,5,7,9]$. Despite numerous studies, the problem of cavitationabrasive wear of hydraulic machines still cannot be considered solved, and a number of theoretical issues remain unclear. The hydraulic structure of the flow was analyzed theoretically and correlations were obtained for the calculation of water intakes. On the basis of experimental data, "Methodical instructions for designing an forebays of large pumping stations" have been developed and empirical dependencies have been proposed, which determine the size and location of elements of the forebays.

\section{Conclusion}

1. The developing methods and systems for maintaining the operating modes of forebays of pumping stations, at which the authors provide minimal resource costs for the hydraulically favorable mode of pumps, experimental studies of forebays, water receivers and main hydraulic elements mating with a pump unit at pump stations Amu-Zang 1, 2

2. Full-scale tests of pump samples included determining the actual parameters of the pumps at the time of the survey, including flow, pump head, unit efficiency, and pump. The parameters of the pumps showed that the units can reduce the flow of $1.75 \ldots 1.29 \mathrm{~m} 3 / \mathrm{s}$ and work with a reduced by $2.4 \ldots 4.2 \%$ efficiency. This provides for the improvement of the forebays regime.

3. The conducted full-scale hydraulic studies of various types of forebays showed the influence of the constructive ratios of the areas of the water intake front and the openings of the suction pipes on the formation of whirlpool areas and the nature of their interaction. A quantitative relationship is established between the kinematic characteristic of the flow in the forebays and the operational performance of the aggregates. An analysis of our experimental data called to establish between the volume of the transit flow and the change in the average velocity along the length of the advance chamber.

4. On the basis of the developed methodology, the design of an advance chamber was recommended and investigated, allowing to improve the performance parameters of the extreme pumping units. The main developments are implemented through a number of operational and design organizations of the Ministry of Water Management of the Republic of Uzbekistan. The annual economic effect was more than 7 million US dollars.

\section{References}

1. Glovatsky O.Y., Nasyrova N.R., Bekchanov F.A. Improving the efficiency of operation of pumping stations of irrigation systems // Scientific and practical journal "Ways to improve the efficiency of irrigated agriculture" - Novocherkassk, №4 (68), pp. 54-58, (2017)

2. Glovatsky O.Y., Nosirov F.Z., SharipovSh.M., Saparov A.B. Study of the effect of cavitation on the pressure pulsation behind the impeller of pumping units // Collection of scientific articles of the XV scientific-practical conference of young scientists and masters "Modern problems in agriculture and water management", Tashkent, pp. 425-430, (2016)

3. A.I. Djurabekov, Sh.R.Rustamov, O.Y.Glovatsky. Mechanism of cavitation and hydroabrasive wear of centrifugal pumps of irrigation pumping stations // Collection of scientific works, SIC ICWC of Central Asia, - Tashkent, pp. 153-159, (2017) 
4. Glovatsky O.Y., Nasyrova N.R., Artikbekova F.K. Some Aspects of Using Pumping Stations in the Development of the Water Resource Sphere of Central Asia in the 21 st Century // Collection of reports of the 20th International Scientific and Practical Conference "The Northern Sea Route, water and land transport corridors as the basis for the development of Siberia and the Arctic in the 21st century". Volume I. Tyumen: TIU, pp. 69-74, (2018)

5. Rustamov Sherzod Rustamovich, Nasirova Naira Ravilevna, Constructive peculiarities of modernized centrifugal pump // European science review, no. 3-4, pp. 278-280, Vienna, (2018)

6. A.I. Azimov, B.B.Hasanov, O.Y.Glovatsky, N.R. Nasyrova. Assessment of the efficiency of operation and safety of pumping stations // Scientific and practical journal "Ways to improve the efficiency of irrigated agriculture" - Novocherkassk, №2 (70), pp. 140-145, (2018)

7. Sh.R.Rustamov, O.Y.Glovatsky New designs and technologies for water and energy saving in systems of machine water lifting // Problems of Energy and Resource Saving. №3-4, pp.143-148, (2017)

8. O.Y.Glovatsky, R.R.Ergashev, N.R. Nasyrova Improving the operational reliability of pumping stations with diagnostic methods // Hydraulic Engineering Construction Magazine No. 12, Moscow, pp. 27-30, (2017)

9. Sh.M.Sharipov, N.R. Nasyrova, A.B.Saparov Ecological and energy-saving problems of reconstructing water-assisted systems // International Scientific and Practical Conference "Ecological Aspects of Land Reclamation, Hydraulic Engineering and Water Management of the Agro-Industrial Complex" (Kostyakovskie readings), Russian Agricultural Academy, pp. 246-249, Moscow, (2017)

10. Glovatsky O.Y., Ergashev R.R., RustamovSh.R. Improving the reliability of operation and water conservation of irrigation pumping stations // Water resources and water use № 3, pp. 9, (Astana 2015)

11. Nasyrova N.R, Nosirov F.Zh., Yusupov N.I. The use of new technical solutions to optimize the regimes of machine-driven water-lifting systems // Scientific and practical journal "Ways to improve the efficiency of irrigated agriculture" - Novocherkassk, №1 (65), pp. 21, (2017)

12. O.Y.Glovatsky, S.Kh.Makhkamov, N.A.Tojibekov, N.R.Nasyrova, N.I.Yusupov Analysis of the uneven movement of water along the length of the water-supplying structures of pumping stations // Proceedings of the Scientific and Practical Conference "Uzbekistan", (pp. 37), T, (2018)

13. Glovatsky O.Y, Nasyrova N. R., Pecheykina E. A. Analysis of criteria values of resource and energy-saving technologies in the operation of pumping stations of irrigation systems // Scientific and practical journal "Ways to improve the efficiency of irrigated agriculture” - Novocherkassk, No. 4 (68), (pp. 25-29) 2017

14. A. Baghlani, Optimized firefly algorithm. Iran international journal of optimization in civil engineering. pp. 6, (Eng. 2012)

15. Ergashev R.R., Mazhidov T.Sh., Glovatsky O.Ya., Azimov A.I., Bekchanov F.A. New methods of dynamic control of the safety of the pump unit of the system of water-lifting // International Scientific Forum "Problems of water and land management" - Russia, pp.153-159, (2015)

16. Glovatsky O.Ya., Ergashev R.R. Reliability assessment in the republic of Uzbekistan. Journal "Perspectives of Innovations, Economics and Businnes" Volume 4. Issue 1. pp. 111-113, (Prague 2010)

17. Shen Xiaoling, Feng Chengjun, Jiang Lanlan. Design of Tingz bridge rainwater pumping station in CBD of Wuxi city. Zhongguo Jishui Paishui, China Water and 
Wastewater. 31, pp. 7, N 12, 2015.

18. Uri Shamir. The Kinnereth section of the national water carrier. Journal of Hydrology. Volume 28, pp. 7, (2016)

19. Tubaldi E., Amabili M., Paidoussis M. Fluid structure. J. Sound and Vibr. pp. 7 (2016)

20. Barton A.F, Mala-Jetmarova H, Analogue of Distribution Systems for Water Use. Mathematical and Computer Modeling, pp. 7, (2017) 